\title{
MEDIA FOTOGRAFI ABAD KE-19: DAGUERREOTYPE, CALOTYPE, DAN COLLODION
}

\author{
Pitri Ermawati \\ Dosen Jurusan Fotografi, Fakultas Seni Media Rekam, ISI Yogyakarta \\ Jalan Parangtritis Km 6,5 Bantul, Yogyakarta \\ No. HP.: 085600001075, E-mail: ermapiet12@gmail.com
}

\begin{abstract}
Abstrak
Artikel ini bermaksud menjelaskan tiga medium fotografi yang lazim digunakan pada abad ke-19, yaitu daguerreotype, calotype, dan collodion. Pembahasan ketiga medium tersebut dititikberatkan pada sejarah kemunculan, teknik pembuatan, dan karakteristik imaji. Baik daguerreotype, calotype, maupun collodion memiliki sejumlah karakteristik yang khas; di samping memiliki kekurangan dan kelebihannya masing-masing. Daguerreotype yang ketajaman imajinya sangat memukau itu memiliki kekurangan pada cetakannya yang tidak dapat diperbanyak. Kekurangan tersebut dapat teratasi oleh calotype yang dapat diperbanyak sampai dengan tidak terhingga. Adapun kekurangan calotype yang berdetail tidak tajam, teratasi oleh collodion yang berdetail tajam sekaligus dapat diperbanyak. Lambat laun setelah dipraktikkan oleh masyarakat, disimpulkan bahwa kekurangsempurnaan medium yang muncul lebih awal akhirnya menjadi penyebab berakhirnya masa kejayaan medium tersebut karena telah hadir medium baru yang bisa mengompensasi kekurangan yang ada.
\end{abstract}

Kata kunci: fotografi, abad ke-19, daguerreotype, calotype, collodion

\begin{abstract}
Photography Media in the $19^{\text {th }}$ Century: Daguerreotype, Calotype, dan Collodion. This article intends to explain three kinds of main stream media in the 19th century; they are daguerreotype, calotype, and collodion. The explanation of the three media is focused on the origin of the media, the techniques of the media, and the characteristics of the image made by each medium. There are some typical characteristics in daguerreotype, calotype, and collodion; they have their own deficiency and excellence. Daguerreotype is amazing in sharpness but lack of reproduction ability. Calotype which came later in public could overcome that lackness because one calotype negative was able to produce unlimited positive images. On the other side, calotype which is less sharp in detail could be solved by the characteristic of the latest medium called collodion which has sharp details and also could be reproduced. Thus, time by time, after being practiced by people, it could be concluded that the imperfect media which had come earlier finally resulted in the elapse of those media because a new medium emerged and was able to compensate the lackness.
\end{abstract}

Keywords: photography, 19th century, daguerreotype, calotype, collodion

\section{PENDAHULUAN}

Kemajuan teknologi telah membuat perubahan besar bagi dunia fotografi. Saat ini teknologi digital telah merambah sendi-sendi kehidupan, tidak terkecuali fotografi. Sistem digital yang menjadi main stream fotografi abad ke-21 telah membuat kegiatan memotret dan mencetak foto menjadi demikian mudah dan praktis. Sekali bidik, foto pun langsung jadi, dan hasilnya dapat langsung dilihat di layar monitor. Jika foto belum memuaskan, fotografer dapat dengan mudah menghapusnya, kemudian mengulangi pemotretan lagi, tanpa repot dan tanpa biaya. 
Berbeda dengan era sekarang yang hanya mengenal satu media main stream yakni fotografi digital, pada era awal eksistensi fotografi yakni abad ke-19 dikenal sejumlah media main stream yang umum digunakan untuk fotografi praksis, seperti daguerreotype, calotype, dan collodion. Ketiga media tersebut memiliki tingkat kesulitan sekaligus kerumitannya sendiri-sendiri. Secara umum, kesulitan dijumpai manakala seseorang tidak mengetahui cara mengoperasikan kamera, tidak mengerti bagaimana mengerjakan proses kamar gelapnya, tidak memahami komposisi bahan-bahan kimia yang mesti digunakan, tidak mengetahui berapa lama exposure time, atau tidak memahami sifat dan karakter media. Selain harus menghadapi kesulitan dan kerepotan, pelaku fotografi masa lalu pun harus menanggung risiko gangguan kesehatan karena selalu bersinggungan dengan bahan-bahan kimia di tempat kerja yang berwujud kamar gelap sempit dan pengap.

\section{LANDASAN TEORI}

\section{Rintisan Awal Fotografi}

Konsep merekam gambar menggunakan cahaya (by the action of light) pada permukaan benda sudah ada sejak zaman Sebelum Masehi, walaupun keberhasilannya baru dicapai setelah berabad-abad kemudian. Eksperimen dan inovasi terus-menerus dilakukan oleh para pioner dalam rentang waktu yang sangat panjang, yang berkaitan dengan tiga ranah: (1) machinal: kamera, tempat terjadinya imaji; (2) optical: lensa, prinsip proyeksi imaji; dan (3) chemical: media/film dan bahanbahan kimia pemroses imaji.

Artikel ini membahas sebagian dari ranah chemical dalam hal tiga media main stream. Pada 1725, seorang profesor anatomi dan ahli fisika Jerman Johann Heinrich Schulze, menemukan substansi peka cahaya silver salt yang kelak akan menjadi material yang vital untuk fotografi. Dalam percobaannya, Schulze mengamati bahwa substansi ini akan bereaksi dan menghitam karena terkena cahaya; bukan karena terkena panas ataupun terpapar udara (teroksidasi). Ini merupakan tonggak sejarah penting dalam fotografi karena bahan kimia peka cahaya cikal-bakal perekam imaji sudah ditemukan. Schulze pun dikenal sebagai peletak kimia dasar fotografi (Editor Time-Life Books, 1970).

\section{Foto Pertama}

Berselang seratus satu tahun sejak ditemukannya silver salt, foto pertama pun tercipta pada tahun 1826. Logam merupakan media pertama yang berhasil digunakan untuk merekam imaji secara fotografis itu. Sejarah mencatat "View from The Wndow at Le Gras" karya Joseph Nicephore Niepce dari Perancis sebagai foto pertama yang berhasil diciptakan oleh manusia (Badger, 2007), (Gernsheim, 1986), dan (Hacking, 2012). Karya yang oleh penciptanya disebut sebagai heliographie yang berarti gambar matahari ini bermedia plat logam berjenis pewter; campuran timah putih dan timah hitam. Plat ini dilumuri dengan apa yang disebut sebagai bitumen Judea, substansi padat sejenis aspal, sebagai materi pelekat bahan-bahan kimia peka cahayanya. Exposure time-nya sangat panjang, sekitar delapan jam.

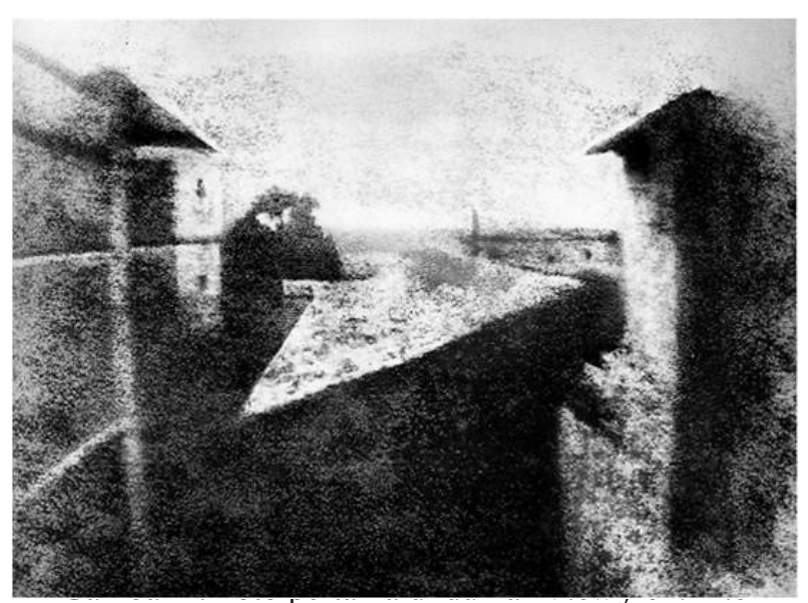

Wndow at Le Gras"

Karya Joseph Nicephore Niepce (1826) 
Subjek foto ini berupa pemandangan yang diambil dari jendela ruang kerja Niepce di rumahnya, di pedesaan dekat Chalon-surSaone, Perancis (Badger, 2007). Karena masih rendahnya kualitas imaji, foto monokrom yang tampak samar-samar ini tidak mudah dikenali apa saja yang menjadi subjeknya. Helmut Gernsheim mendeskripsikan bagian per bagian dari visual foto tersebut. Disebutkan olehnya bahwa subjek di sebelah kiri itu adalah rumah burung dara, sebatang pohon pir dengan sekelumit langit yang muncul di antara gerumbul dedaunannya; di bagian tengah adalah atap miring dari sebuah gudang; dan di sebelah kanan itu adalah sebagian sisi sayap dari rumah tempat tinggal Niepce (Gernsheim, 1986).

\section{Kamar Gelap}

Fotografer abad ke-19 tidak dapat dipisahkan dari kamar gelap (dark room). Kamar gelap merupakan ruangan sejenis laboratorium, tempat fotografer bekerja dengan bahan-bahan kimia. Karena bahan-bahan kimia yang dipakai bersifat reaktif terhadap cahaya, ruangan tersebut sengaja dibuat gelap. Di dalam ruangan ini, selain memproses film menjadi foto, fotografer pun menyiapkan plat atau lembaran kertas untuk dibuat peka/sensitif cahaya, dan menjadi sebuah film. Adapun perlengkapan standar kamar gelap seperti yang disebut oleh Nugroho (2006) terdiri atas alat pembesar (enlarger), lampu aman (safe lamp), perangkat pengembang (developing and processing equipment), dan bahan-bahan kimia lainnya.

\section{Prinsip Kerja Fotografi Kimiawi}

Untuk memahami bagaimana fotografi abad ke-19, cara mendapatkan foto dengan proses kimiawi perlu dijelaskan. Fotografi kimiawi yang dimaksud pada subjudul di atas merujuk pada penggunaan bidang datar/plat/lembaran tempat menyimpan imaji (film), substansi pemuncul imaji (developer), substansi penetap imaji (fixer), dan plat/lembaran foto jadi, yang tidak dapat dipisahkan dari penggunaan bahan-bahan kimia.

\section{Film}

Film merupakan media peka cahaya yang digunakan untuk merekam imaji. Permukaan film yang menghadap ke arah cahaya mengandung lapisan atau emulsi peka cahaya, yang umumnya bermaterikan perak-perakan atau garam-garaman, seperti silver chloride dan silver salt. Lembaran film pada era modern abad-20 sampai dengan abad ke21 menggunakan bahan dasar pita seluloid. Adapun lembaran film pada era abad ke-19 bermacammacam jenisnya; ada yang berupa logam seperti yang digunakan dalam proses daguerreotype dan tintype collodion; kertas seperti yang digunakan dalam calotype dan wax paper negative; serta ada yang berupa kaca seperti yang digunakan dalam proses ambrotype collodion dan albumen negative.

\section{Developer}

Pada fotografi analog, film yang tercahayai di dalam kamera saat pemotretan membentuk imaji laten. Imaji ini kemudian dikembangkan dengan bahan penimbul imaji yang disebut dengan developer. Dalam proses fotografi dengan film, calotype, dan collodion, developer ini berwujud larutan kimiawi; sedangkan dalam proses daguerreotype berwujud uap merkuri yang didapatkan dengan cara memanaskan merkuri dengan pelita. Pekerjaan menimbulkan imaji laten ini dilakukan di dalam ruangan yang kedap cahaya bernama kamar gelap (dark room).

\section{Fixer}

Imaji yang muncul dari proses pengembangan (developing) perlu di-fix-kan atau ditetapkan, supaya tidak "hangus terbakar" manakala terus-terusan terpapar cahaya. Sama dengan developer, fixer ini berwujud larutan. Film yang sudah dikembangkan selanjutnya di-fix-kan 
dengan cara dibasuh atau direndam dengan larutan fixer ini. Setelah proses ini, foto yang tercipta sudah "aman" dari paparan cahaya, tidak akan lagi mengalami penghitaman.

\section{Foto}

Hasil akhir proses fotografi adalah foto (photo), yang berupa imaji positif dua dimensi. Foto abad ke-19 hanya terdiri atas dua warna, yaitu hitam dan putih, belum berwarna. Walaupun sama-sama hitam putih, namun hitam putih pada daguerreotype, calotype, dan collodion, memiliki color cast yang berbeda-beda.

\section{PEMBAHASAN}

\section{Daguerreotype (1839 - Pertengahan 1850-an)}

\section{Kemunculan Daguerreotype}

Berhasil dibuatnya foto pertama oleh Joseph Nicephore Niepce sebagaimana telah disebutkan dalam bab terdahulu telah menarik perhatian Louis Jacques Mande Daguerre, seorang pengusaha seni pertunjukan dan pelukis diorama dari Paris, Perancis. Ia selanjutnya berkorespondensi dengan Niepce untuk menawarkan kerja sama. Kesepakatan pun tercapai dengan ditandatanganinya kontrak kerja pada tahun 1829. Inti kontrak kerja itu adalah upaya memperbaiki kualitas imaji heliographie (Gernsheim, 1986). Sebelum proyek kerja sama ini selesai, pada tahun 1833 Niepce wafat (Hacking, 2012). Proyek pun akhirnya dilanjutkan oleh Daguerre seorang diri.

Obsesi Daguerre demikian besar untuk dapat membekukan fleeting image yang berasal dari proyeksi lensa. Pada masa itu, hal ini merupakan sesuatu yang dianggap mustahil dan mengada-ada. Setelah melakukan percobaan-percobaan dengan berbagai macam material dan bahan kimia, Daguerre akhirnya mendapatkan hasil. Ia berhasil membuat foto bermedia tembaga yang diberi nama sesuai dengan namanya: "daguerreotype". Fotografi telah berhasil mencapai kualitas gambar sebagaimana yang diinginkan olehnya, dan oleh masyarakat pada umumnya, yakni jelas dan tajam. Pada 19 Agustus 1839, daguerreotype resmi diumumkan ke publik oleh pegawai pemerintah Perancis bernama Francois Arago. Pemerintah Perancis membeli paten daguerreotype, dan atas penemuannya yang begitu berguna untuk masyarakat luas ini, Daguerre dan juga Isidore Niepce, anak Joseph Nicephore Niepce mendapatkan sejumlah imbalan materi dan uang pensiun dari pemerintah Perancis. Daguerreotype pun berhasil secara komersial dan kepopulerannya cepat menyebar ke negara-negara lain di Eropa hingga Amerika, kecuali Inggris dan Wales yang terikat hak paten.

Badger (2007) menyebut rival utama daguerreotype adalah calotype ciptaan William Henry Fox Talbot; mirror of nature versus photogenic drawing. Meskipun unggul dalam hal detail, daguerreotype kalah dalam hal ketidakmampuan reproduksi foto. Sebaliknya, meskipun kalah dalam kecemerlangan imaji, calotype mampu memenuhi kebutuhan dan keinginan manusia modern dalam hal jumlah foto; karena selembar kertas negatif calotype bisa menghasilkan foto positif yang banyak, dan bahkan tidak terbatas jumlahnya selama negatif tersebut masih ada. Dikatakan lagi oleh Badger (2007) bahwa faktor gemilangnya kemampuan repoduksi foto inilah yang pada akhirnya membuat calotype menggantikan eksistensi daguerreotype.

\section{Teknik dan Karakteristik Daguerreotype}

Langkah-langkah proses daguerreotype sebagaimana tertulis dalam buku petunjuk daguerreotypie "Historique et Description des Procedes du Daguerreotype et du Diorama" (Gernsheim, 1986) adalah: (1) plat tembaga berlapis perak (silver-plated copper), diberi zat peka cahaya uap iodine, membentuk silver iodide pada plat; (2) plat dipasang pada kamera; (3) pemotretan, muncul imaji laten; (4) dikembangkan dengan uap 
merkuri yang dipanaskan dengan lampu spiritus; (5) ditetapkan dengan soda hyposulphite (hipo); (6) dibilas dengan air suling; dan (7) hasil: imaji positif berdetail sangat bagus/tajam.

Daguerreotype merupakan foto monokrom hitam-putih bermedia plat tembaga berlapis perak, dengan nuansa kebiruan-keperakan atau silvery bluish. Detail subjek di dalam foto daguerreotype tampak sangat tajam dan jelas. Detail imaji yang sangat tinggi pada permukaan glossy itu mampu memukau orang-orang yang melihatnya. Selain faktor monokromnya yang mengurangi kerealistisan gambar, bisa dikatakan imaji daguerreotype sangat persis dengan objek aslinya, ibarat melihat bayangan di cermin. Hal ini sejalan dengan yang dikatakan oleh Badger (2007), bahwa imaji daguerreotype memiliki tingkat kejernihan dan detail yang ekstrim.

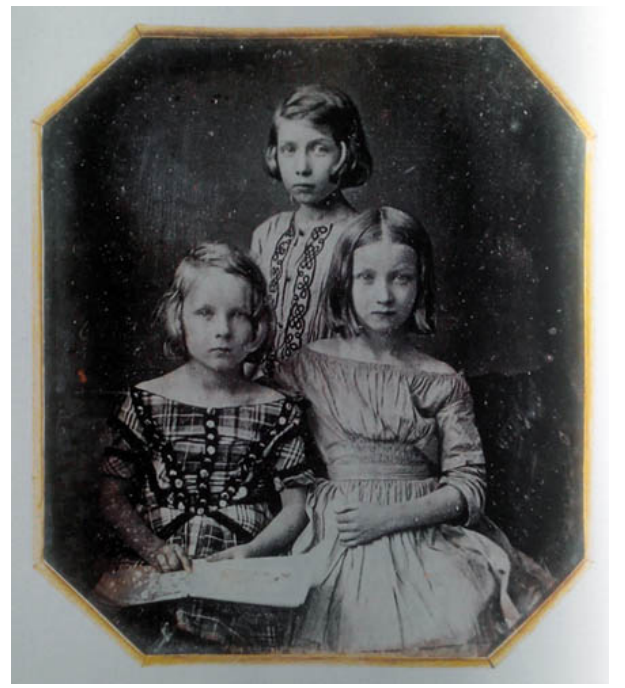

Gambar 2. Foto daguerreotype yang berdetail tajam

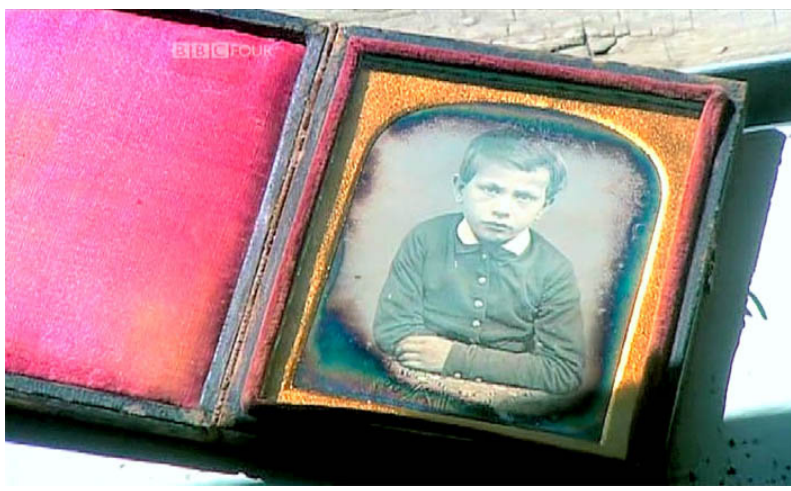

Gambar 3. Potret daguerreotype seorang anak yang tampak realis dengan detail tinggi
Di samping keunggulan tersebut, daguerreotype juga memiliki kekurangan yang disebut dengan cul de-sac in photography: foto daguerreotype tidak dapat diperbanyak. Gambar yang didapatkan dari plat logam yang diekspos di dalam kamera, kemudian dikembangkan dan di$f i x$-kan itulah yang menjadi satu-satunya fotonya. Jika menghendaki lebih dari satu foto, orang harus memulai lagi prosesnya dari awal, dari mempersiapkan plat logam lainnya, mengeksposnya, mengembangkannya, hingga mem-fix-kan imaji yang muncul pada permukaan plat logam tersebut.

Cara orang menangani dan menyimpan daguerreotype sungguh spesial. Permukaan daguerreotype yang glossy memang berhasil menyajikan imaji dengan ketajaman yang mengagumkan, tetapi hal ini sekaligus menjadi kekurangannya. Daguerreotype riskan terhadap goresan dan sentuhan, bahkan sentuhan ujung jari sekalipun. Maka dari itu, foto daguerreotype perlu diperlakukan dengan sangat berhati-hati, biasanya dikemas dengan bingkai berpenutup. Untuk memberikan kesan elegan dan mewah, umumnya bingkai tersebut diberikan ukir-ukiran berwarna emas, diberi kaca, dan dikemas dengan wadah berbentuk album mini berbahan kulit. Album tersebut biasanya diberi tulisan serta ukir-ukiran bertinta emas.

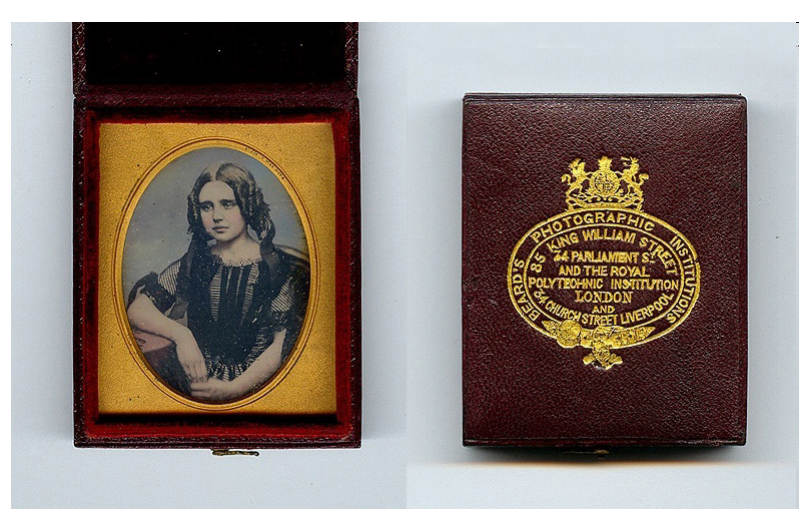

Gambar 4. Portret daguerreotype yang diwarnai dengan tangan, disimpan di dalam wadah kulit berembos "Beard's Photographic Institution" 
Para pemilik foto daguerreotype cenderung menyimpan foto mereka dengan cara tersebut di atas, dan tidak memasangnya di dinding sebagai pajangan. Imaji daguerreotype yang brilian berkilauan itu memiliki kekurangan yang tidak dapat diatasi: ketika seseorang melihat ke arah foto, imaji bisa tampak negatif, positif, atau bahkan kombinasi keduanya; tergantung pada sudut pandang orang tersebut dan arah cahaya yang jatuh pada foto. Oleh sebab itu, foto daguerreotype tidak dapat dinikmati dengan cara digantungkan di dinding seperti halnya lukisan.

\section{Calotype (1841 - Akhir 1850-an)}

\section{Kemunculan Calotype}

Pada masa yang bersamaan dengan percobaan-percobaan fotografis yang dilakukan oleh Daguerre, di Inggris, seorang tuan tanah kaya dan terpelajar bernama William Henry Fox Talbot melakukan sejumlah percobaan pula dengan bahan-bahan kimia peka cahaya bermedia kertas. Percobaan tersebut menghasilkan proses fotografi yang oleh para kolega Talbot disebut sebagai talbotype. Talbot sendiri menyebut penemuannya ini dengan "calotype"; yang diambil dari kata-kata berbahasa Yunani "kalos" yang berarti “indah", dan "typos" yang berarti "impresi” (Editor Time-Life Books, 1970). Ini merupakan sebuah penemuan besar yang menjadi dasar bagi sistem fotografi modern, dengan kemampuannya mereproduksi foto positif yang tidak terbatas jumlahnya.

Tidak seperti daguerreotype yang patennya dibeli oleh pemerintah Perancis, untuk kemudian dibebaskan penggunaannya bagi masyarakat, Talbot mendaftarkan patennya pada 1841 dengan nomor 8842 (medley.co.uk, diakses pada 12 November 2016, pukul 17.14 WIB). Dengan demikian, siapa saja yang memanfaatkan penemuannya itu untuk kepentingan komersial dikenakan sejumlah biaya. Empat belas tahun berselang, pada tahun 1855 paten ini mulai terusik oleh kehadiran teknik fotografi baru yang dipopulerkan oleh sesama orang Inggris bernama Frederick Scott Archer, yang disebut dengan collodion atau teknik wet plate collodion. Mirip dengan calotype, penemuan Archer ini pun berupa imaji negatif, tetapi pada permukaan kaca, bukan kertas. Eksistensi calotype pun melemah dan akhirnya tergantikan seiring dengan kehadiran teknik wet plate collodion yang bebas paten serta memiliki kecemerlangan gambar yang lebih tinggi.

\section{Teknik dan Karakteristik Calotype}

Pada 8 Februari 1841 Talbot mematenkan "calotype" atau "talbotype" (Gernsheim, 1986) yang prosesnya adalah: (1) kertas tulis berkualitas baik, dilapisi larutan silver nitrate \& potassium iodide, yang menjadi silver iodide, ditambah kepekaannya dengan larutan gallic acid \& silver nitrate; (2) pemotretan; muncul imaji laten; (3) imaji laten dikembangkan dengan larutan perak gallo nitrate; (4) dihangatkan dengan api $1-2$ menit, gambar laten menjadi tampak; (5) hasil berupa negatif di-fix-kan dengan potassium bromide; (6) dibilas dengan air; (7) hasilnya berupa kertas berimaji negatif; (8) untuk menghasilkan maji positif, kertas negatif ditumpukkan pada photogenic drawing paper, ditindih kaca transparan, kemudian disinari di bawah sinar matahari tanpa membutuhkan proses pengembangan lagi; dan (9) gambar positif dapat diperbanyak dengan jumlah tak terhingga.

Badger menyebut calotype ciptaan Talbot sebagai "rival" bagi daguerreotype ciptaan Daguerre yang sudah eksis terlebih dahulu. Secara singkat, tekniknya dimulai dari menyiapkan kertas tulis biasa, membuatnya peka cahaya dengan larutan kimia, mengeksposnya di dalam kamera, mengembangkan dan menetapkan imaji, kemudian bermuara pada hasil imaji yang terbalik tonal alaminya. Hasil proses pertama ini disebut dengan “negatif” (Badger, 2007). Untuk membuat foto positif, perlu dilakukan satu 
kali lagi proses yakni proses mencetak foto secara kontak atau contact print.

Kamus Fotografi mengartikan contact print sebagai suatu cetakan foto yang dihasilkan dengan cara mengontak (menempelkan) langsung negatif (klise) pada kertas cetak foto secara rapat, lalu disinari (Nugroho, 2006). Sama halnya dengan itu, Badger menerangkan kelanjutan proses pertama tadi bahwa cetakan foto dibuat dengan cara menyiapkan lagi selembar kertas peka cahaya, kemudian menumpuknya dengan kertas negatif yang bertonal terbalik tadi, lalu mengeksposnya dengan cahaya (Badger, 2007). Istilah "negatif" dan "positif" sendiri tidak dicetuskan oleh Talbot, tetapi oleh seorang Inggris lainnya bernama Sir John Herschel (Turner, 1987).

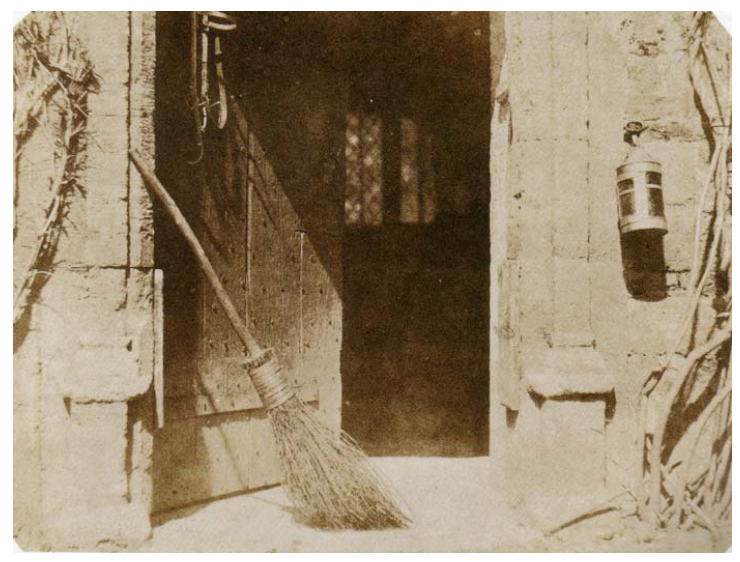

Gambar 5. Salted paper print dari negatif calotype Karya William Henry Fox Talbot (1843) ini berjudul The Open Door

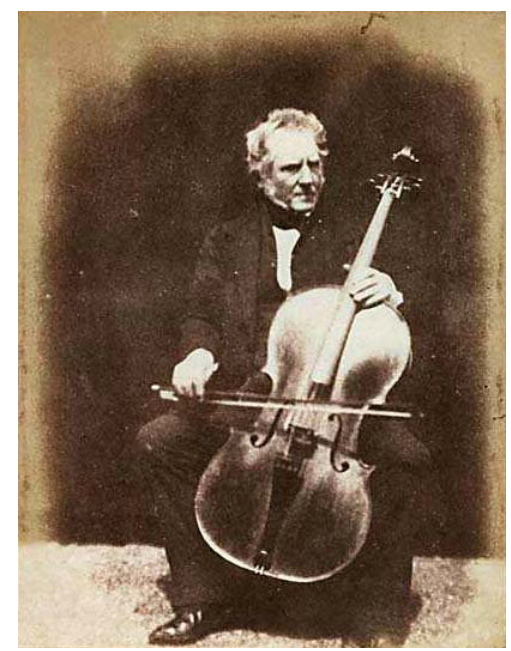

Gambar 6. Calotype berwarna cokelat hangat
Kualitas imaji calotype tidak secemerlang dan setajam daguerreotype. Hal ini bisa demikian karena dipengaruhi oleh kualitas kertas yang dipakai sebagai mediumnya. Baik ketas film maupun kertas foto memiliki serat atau tekstur. Foto yang terbentuk menjadi jauh lebih soft dibandingkan dengan foto daguerreotype yang berpermukaan licin mengkilap. Garis-garis subjek kehilangan tepiannya yang tegas, detailnya pun mengabur.

Walaupun demikian, dari satu kertas negatif yang tercipta dalam proses pertama, foto calotype dapat diperbanyak sejumlah yang diinginkan, sampai tak terhingga jumlahnya. Hal ini menjadi kelebihan calotype dibandingkan dengan daguerreotype.

Kelebihan lainnya, karakter kertas yang ringan dan tipis membuatnya dapat dimasukkan ke dalam buku, sehingga buku pun bisa dilengkapi dengan gambar berwujud foto yang memiliki tingkat realitas tinggi dibandingkan gambar tangan. Dengan demikian, gambar calotype pada buku mampu membantu pemahaman pembacanya akan suatu hal yang membutuhkan gambar realis. Selain itu, persebarannya melalui buku membuat imaji foto calotype relatif lebih mudah dinikmati, dan eksistensi calotype pun menjadi lebih mudah tersebarluaskan. The Pencil of Nature adalah

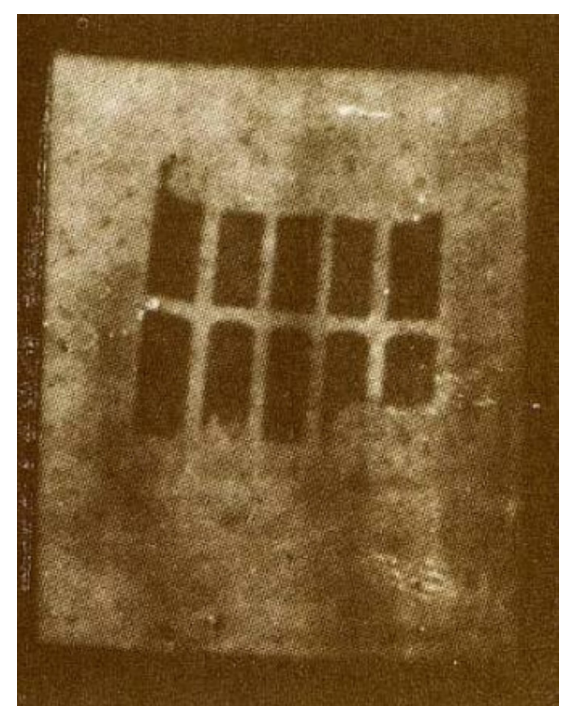

Gambar 7. Calotype negatif berwarna cokelat hangat Karya berjudul Latticed Window (1835) ini merupakan negatif foto pertama di dunia 
buku komersial pertama yang berilustrasikan foto hasil pemotretan dengan kamera (24 gambar calotype) yang dibuat oleh Talbot pada tahun 1844 (Gernsheim, 1986).

Eksistensi calotype mulai terusik saat Frederic Scott Archer mulai memasyarakatkan proses fotografi plat basah dengan collodion. Hal ini membuat Talbot gusar. Pada 1855 Talbot mengajukan keberatan atas penemuan Archer tersebut yang dianggapnya menyerupai calotype karena sama-sama menghasilkan gambar negatif dari material transparan yang gambar positifnya bisa diperbanyak. Hal ini dianggapnya melanggar hak paten atas calotype. Meskipun demikian, pengadilan Inggris tidak mengabulkan keberatan Talbot. Ini dikarenakan oleh faktor pembedanya yang signifikan dalam hal bahan, proses, dan hasilnya, yang walaupun ada kemiripan namun sejatinya berbeda (www.medley.co.uk, diakses pada 12 November 2016, pukul 17.14 WIB). Proses collodion yang bebas paten membuat semua kalangan masyarakat, baik dari ranah komersial maupun amatir bebas berfotografi. Kecemerlangan imaji collodion yang bebas dari pengaruh serat kertas pun membuatnya menjadi kian populer, hingga lambat laun memupus eksistensi calotype.

\section{Collodion (1851 - Awal 1880-an)}

\section{Kemunculan Collodion}

Collodion yang dalam bahasa Yunani berarti lem (Prakel, 2010) adalah bahan kimia cair yang bertekstur lengket seperti sirup. Substansi ini digunakan untuk melapisi plat atau lembaran medium supaya bahan-bahan kimia peka cahaya dapat menempel pada medium tersebut. Disebut wet plate process atau proses plat basah karena plat berlapis collodion hanya bisa digunakan untuk memotret selagi masih basah; karena plat yang masih basah memiliki sensitivitas yang baik terhadap cahaya. Jika didiamkan, semakin lama plat akan semakin mengering dan kehilangan sensitivitasnya terhadap cahaya. Selain itu, pascapemotretan, selagi masih basah, plat juga harus segera diproses; karena jika tidak, imaji latennya akan memudar dan menghilang seiring dengan keringnya plat.

Selama 12 tahun pertama, fotografi didominasi oleh daguerreotype dan calotype. Pada 1851 Frederick Scott Archer, pria berkebangsaan Inggris memperkenalkan sebuah improvisasi, yakni wet-plate collodion process atau proses collodion plat basah. The Chemist edisi Maret 1851 memuat publikasi tersebut. Gernsheim (1986) menambahkan bahwa sebetulnya sebelum itu, Robert J. Bingham dan Gustave Le Gray telah disebut-sebut sebagai orang yang secara independen meyakini tentang kemungkinan digunakannya collodion untuk fotografi, namun mereka sendiri belum pernah mempublikasikan satu pun percobaan yang berhasil. Archer sendiri adalah seorang pemahat yang juga belajar membuat calotype. Ia memanfaatkan calotype untuk memotret para sitter-nya sebagai bahan studi pahatannya. Selain itu, melalui percobaan-percobaan kimiawinya, ia mengupayakan perbaikan kualitas kertas calotype dengan cara melapisinya dengan berbagai macam substansi, termasuk collodion yang belum lama ditemukan. Ide menggunakan collodion sebagai pengganti kertas pun akhirnya muncul.

Tidak seperti media-media pendahulunya, yakni daguerreotype dan callotype yang dipatenkan; oleh Archer proses collodion ini dibebaskan dari paten sehingga semua orang bisa berfotografi dengan collodion. Kepopuleran collodion pun semakin meningkat, bahkan proses fotografi collodion dapat terus bertahan selama 30 tahunan, dari awal tahun 1850-an hingga tahun 1880-an.

Meskipun begitu, kekurangan proses collodion yang mengharuskan "proses cepat di tempat" tidak dipungkiri telah membuat repot dan tidak nyaman para pelaku fotografi. Kerepotan 
lebih dirasakan oleh fotografer outdoor yang hendak memotret landscape atau bangunan. Mereka harus membawa serta tenda kamar gelap beserta seperangkat alat untuk memproses fotonya ke mana pun mereka pergi. Ini berarti, fotografer harus membawa plat kaca yang berat dan rentan pecah; botol-botol berisi air, developer, dan fixer; serta tenda dan kamera. "Terbenamnya fotografer di dalam pakaian kamar gelapnya" ini merupakan kekurangan utama collodion. Mereka menginginkan proses yang lebih nyaman dan praktis. Percobaanpercobaan pun dilakukan di mana-mana, oleh siapa saja yang tertarik dengan fotografi. George Eastman, seorang warga Amerika Serikat termasuk salah satu di antaranya. Percobaan-percobaannya pada 1880-an awal akhirnya membuahkan hasil berupa film dengan emulsi gelatin kering yang ringan dan praktis. Ditunjang dengan penemuannya berikutnya yang berupa kamera box merk "Kodak" yang simple dan kecil pada 1888, dan layanan jasa proses cuci film dan cetak foto, fotografi pun akhirnya menjadi semakin mudah dan praktis. Tidak hanya para profesional dan penghobi serius, namun para amatir tidak terkecuali anak kecil dan ibu-ibu bisa berfotografi. Era fotografi amatir pun menjadi terbuka lebar. Secara pelan namun pasti, akhirnya proses collodion pun akhirnya tergantikan.

\section{Teknik dan Karakteristik Collodion}

Berikut ini adalah langkah-langkah proses fotogafi collodion yang diperkenalkan oleh Archer, sebagaimana dituliskan oleh Gernsheim (1986): (1) collodion berupa potassium iodide, ditumpahkan merata pada plat kaca dengan cermat dan berhatihati; (2) proses sensitivasi: plat dicelupkan de dalam larutan silver nitrate; (3) pemotretan, muncul imaji laten (harus segera disinari/digunakan untuk memotret selagi basah, karena sensitivitas akan semakin berkurang jika collodion mengering); (4) dikembangkan dengan pyrogallic acid atau ferrous sulphate (harus langsung dikembangkan, karena imaji laten akan menghilang seiring mengeringnya plat); dan (5) gambar di-fix-kan dengan soda hyposulphite atau potassium cyanide.

"Collodion was a gluey liquid" (Sandler, 2002). Collodion adalah bahan cair yang lengket. Badger melengkapi deskripsi yang diberikan oleh Sandler itu bahwa collodion merupakan benda cair lengket semacam sirup yang berbahan dasar gun cotton yang dijual di pasaran bebas, dilarutkan dengan ether atau alkohol, dan ditambahkan iodide salts (Badger, 2007). "Sirup" ini digunakan untuk melapisi plat yang berfungsi sebagai "fondasi” film, supaya dapat mengikat emulsi peka cahaya yang diratakan di atasnya.

Bahan utama pembentuk collodion adalah gun cotton, yang memiliki nama lain nitrocellulose, cellulose nitrate, atau flash paper, yang merupakan campuran kimiawi yang mudah terbakar, yang dihasilkan dengan cara menitratkan selulose dengan zat pembuat nitrat, semisal nitric acid (asam sitrat). Bahan lainnya berupa ether, yang merupakan substansi berwujud cairan transparan tanpa warna, yang mudah menguap bila terpapar udara.

Tidak seperti foto calotype yang ketajaman gambarnya tidak sempurna karena pengaruh tekstur serat kertas yang tidak bisa disembunyikan, foto dari wet collodion process memiliki detail yang tajam. Ketajaman detail ini diperoleh dari permukaan

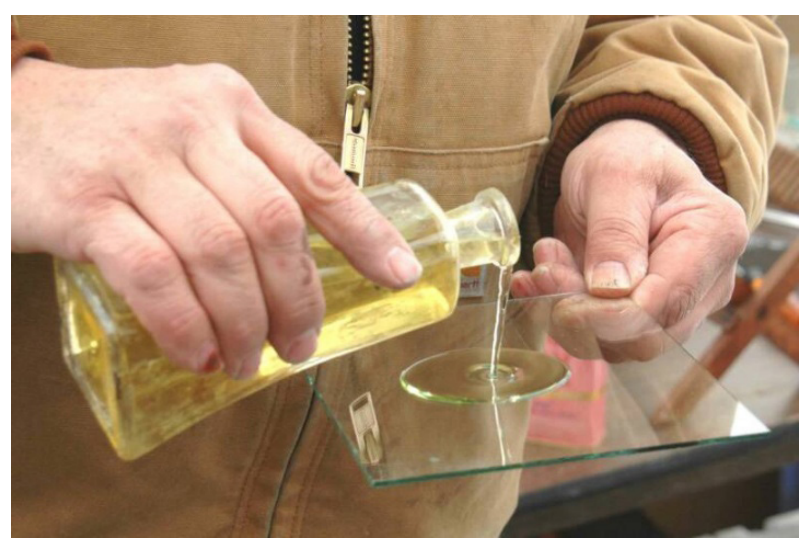

Gambar 8. Collodion ditumpahkan di atas plat kaca Sumber: www.tintypeforever.com

Diakses pada 22 September 2016, pukul 12.43 WIB 
materi kaca atau logam berlapis "sirup" collodion yang glossy, sebagaimana glossy-nya permukaan daguerreotype; bahkan ketajamannya dianggap sejajar dengan daguerreotype itu sendiri.

\section{Varian Foto Collodion}

\section{Berbeda dengan daguerreotype dan} calotype yang masing-masing memiliki satu varian saja, proses collodion memiliki dua varian yang populer: plat kaca atau ambrotype, dan plat besi atau ferrotype alias tintype. Sebetulnya ada satu varian lagi namun dianggap kurang populer, yakni artrograph yang bermedia kulit atau kertas yang diwarnai hitam. Penelitian ini membahas dua varian yang populer saja yang disebutkan di awal, yaitu ambrotype dan tintype.

\section{a. Ambrotype}

Ambrotype merupakan sebuah variasi dari proses collodion, sebagai hasil kolaborasi Archer dan Peter Wicken Fry. Adapun istilah "ambrotype" diberikan oleh Marcus A. Root, fotografer daguerreotype Philadelphia yang juga tinggal di Inggris. Menurut (Editor Time-Life Books, 1970), istilah ambrotype berasal dari bahasa Yunani "ambrotos" yang berarti abadi (immortal), dan "typos" yang berarti imaji (image). Ambrotype merupakan foto positif langsung pada kaca, yang didapatkan dengan cara mem-bleaching negatif collodion yang underexposed, dan menjadikannya tampak sebagai gambar positif dengan memberikan latar belakang gelap, dilihat dengan cahaya pantulan. Jadi, satu plat bisa dilihat sebagai negatif (klise) dan positif (foto) sekaligus, tergantung pada bagaimana cara melihatnya.

Ambrotype memiliki kesamaan dengan calotype dalam hal kemampuannya menghasilkan klise (imaji negatif) dan foto (imaji positif), namun berbeda dalam hal plat kaca sebagai filmnya. Foto bisa dihasilkan dengan melakukan satu langkah lagi, yaitu mencetak kontak klise kaca tersebut dengan

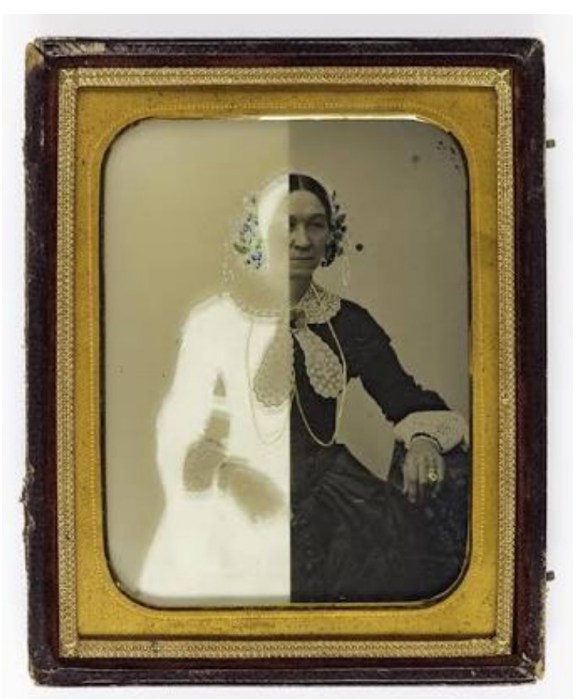

Gambar 9. Sebuah foto collodion dilihat dengan dua cara: tanpa background gelap yang tampak negatif (kiri), dan dengan background gelap yang tampak positif (kanan).

kertas peka cahaya, biasanya berupa albument paper atau salted paper. Kertas tersebutlah yang menjadi hasil akhir foto positifnya, yang jumlahnya bisa dibuat dalam jumlah tidak terbatas.

\section{b. Tintype}

Selain ambrotype, terdapat teknik lain yang populer di kalangan masyarakat khususnya golongan menengah ke bawah, yakni memakai film yang terbuat dari logam yang sudah disepuh hitam. Teknik ini terkenal dengan sebutan "ferrotype" atau "tintype" yang menghasilkan imaji positif langsung (direct positive). Disebut "ferrotype" karena teknik ini menggunakan bahan ferrum atau besi; disebut "tintype" karena teknik ini menggunakan bahan tin atau timah/kaleng/blek sebagai mediumnya. Dibandingkan dengan daguerreotype yang samasama menggunakan plat tembaga berlapis perak, tintype ini berbiaya rendah sehingga membuat fotografi dapat dijangkau oleh kalangan pekerja marjinal dan rakyat jelata pada umumnya.

Editor Time-Life Books (1970) menyebut, pada tahun 1850 setelah diperkenalkannya ambrotype yang ekonomis, Hannibal L. Smith, profesor kimia di Kenyon College, mematenkan 


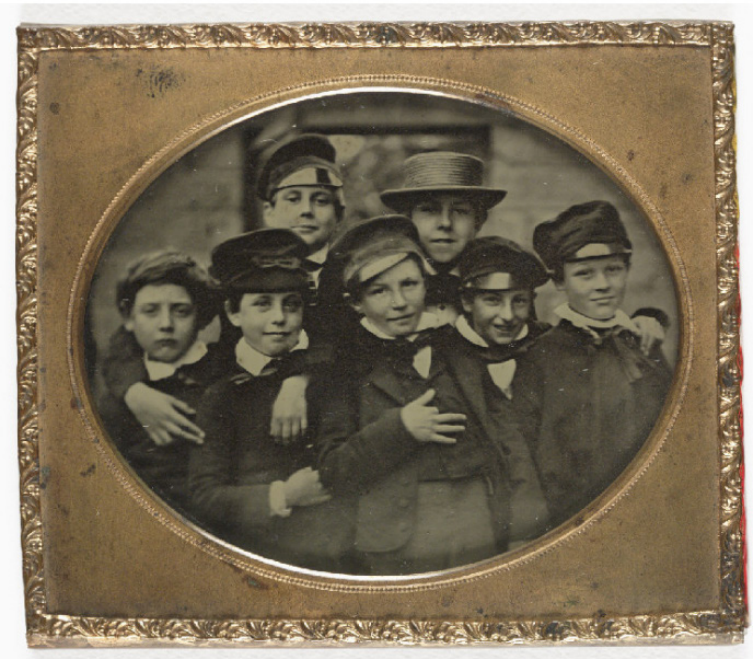

Gambar 10. Potret tintype dengan nuansa abu-abu yang kuat

quick-service tintype, yang juga berbiaya murah. Proses tintype ini bahkan lebih cepat daripada ambrotype dalam hal sampainya foto ke tangan pelanggan. Kecepatan pelayanan itu didapatkan dari formula baru larutan-larutan pemroses, yang merupakan penentu biaya murah tintype. Sama halnya dengan ambrotype, tintype juga merupakan wet-plate collodion negative di atas background gelap, yang menghasilkan imaji positif. Hanya saja, plat kaca ber-background kain gelap atau bervernis gelap digantikan dengan lembaran metal, yang biasanya berupa besi tipis yang berenamel hitam atau coklat gelap, sebagai penyangga collodion.

Murahnya tintype dengan cepat mewabah di masyarakat pada era itu. Usahawan tintype pun bermunculan di mana-mana. Mereka acap kali tampak sedang mengambil gambar anak-anak di taman, keluarga-keluarga yang sedang piknik, dan pasangan pengantin yang baru saja menikah di sekitar gereja. Ratusan ribu pemuda pun secara sadar berpose dengan gagahnya di depan kamera tintype sebelum mereka berangkat ke Civil War. Foto-foto yang dihasilkan umumnya mentah dan sederhana, tetapi di tangan fotografer berbakat, proses tintype pun dapat menghasilkan potret yang menakjubkan.

Foto tintype konvensional tidak dapat diperbanyak. Untuk menyiasati hal tersebut, para fotografer menggunakan kamera multilensa untuk mendapatkan beberapa gambar dengan sekali bidik, guna mengakomodasi siapa saja yang ingin memiliki foto diri dalam jumlah ekstra.

\section{SIMPULAN}

Sebagai media fotografi main stream abad ke-19, baik daguerreotype, calotype, maupun collodion memiliki sejumlah karakteristiknya yang khas. Masing-masing medium juga memiliki sisi kelebihan dan kekurangan. Foto berbasis tembaga bersepuh perak daguerreotype yang silvery bluish dikagumi karena detail imajinya yang tajam, namun memiliki kelemahan, yaitu tidak dapat diperbanyak. Hal ini berbanding terbalik dengan calotype. Dengan hasil foto berbasis kertas yang berpermukaan matte, calotype tidak memiliki detail bagus, namun jumlah foto dapat diperbanyak hingga tak terbatas. Calotype dipandang sebagai medium yang mampu memenuhi kebutuhan manusia modern. Keuntungan yang didapatkan dari proses calotype itu lambat laun menggerus eksistensi daguerreotype. Begitu pula dengan collodion yang bermedia kaca dan logam murah, sebagai medium yang paling muda di antara ketiganya. Collodion yang bebas dari hak paten memiliki ketajaman gambar yang dapat disandingkan dengan daguerreotype. Pada ambrotype atau collodion berbasis kaca, jumlah foto pun dapat diperbanyak. Ini merupakan keunggulan collodion yang pelan namun pasti menggerus eksistensi calotype. Walaupun demikian, collodion memiliki kelemahan, yaitu riskan pecah dan tidak praktis. Collodion pun akhirnya tersingkirkan pula dengan hadirnya medium albumen paper dan medium film berbasis emulsi gelatin buatan Kodak yang ringan, lebih mudah penggunaannya, serta praktis. "Gelatin has been the medium of choice in which to disperse and coat photographic materials for well over 100 years, " sebut Rogers (2007). Film gelatin inilah yang pada akhirnya bertahan paling 
lama hingga seratus tahunan, hingga memasuki era fotografi digital pada abad ke-21.

\section{KEPUSTAKAAN}

Badger, G. (2007). Light and Film. London: Quadrille.

Editor Time-Life Books. (1970). Light and Film. Mallorca: Time-Life Books.

Gernsheim, H. (1986). A Concise History of Photography. New York: Dover Publication.

Hacking, J. (2012). Photography, The Whole Story. London: Thames \& Hudson.

Nugroho, A. (2006). Kamus Fotografi. Yogyakarta: Penerbit Andi.

Prakel, D. (2010). The Visual Dictionary of Photography. Case Postale: Ava Publishing.

Rogers, D. (2007). The Chemistry of Photography. Middlesex: Danercon Ltd.

Sandler, M. W. (2002). Photography: An Illustrated History. New York: Oxford University Press.

Turner, P. (1987). History of Photography. Greenwich: Brompton. 